\title{
UTILIZAÇÃO DE PLASMA RICO EM PLAQUETAS NO TRATAMENTO DE FERIDA CUTÂNEA EM CÃO: RELATO DE CASO
}

Jade Marina Vidal ${ }^{1}$

Luciana Hugue de Souza $\mathrm{Zat}^{2}$

VIDAL, J. M.; ZAT, L. H. de S. Utilização de plasma rico em plaquetas no tratamento de feridas cutâneas em cão: relato de caso. Arq. Ciênc. Vet. Zool. UNIPAR, Umuarama, v. 22, n. 2, p. 59-64, abr./jun. 2019.

RESUMO: O plasma rico em plaquetas (PRP) consiste em um concentrado suprafisiológico de plaquetas extraído a partir do sangue autógeno do paciente e centrifugado adequadamente. O presente relato descreve a utilização do PRP no tratamento de ferida cutânea, após exérese de massa com evolução de 4 meses em um cão fêmea, da raça Beagle, de 7 anos de idade. Citologia aspirativa por agulha fina (CAAF) foi realizada na massa e diagnóstico sugestivo de neoplasia de anexo cutâneo de baixo grau foi identificado. $\mathrm{O}$ tratamento instituído consistiu na excisão da massa e aplicações tópicas e intradérmicas do produto obtido nos bordos da ferida. A lesão apresentou diminuição da resposta inflamatória, cicatrização limpa, bordos uniformes, e ausência de exsudato purulento, tecido de granulação exagerado e complicações sob o caráter neoplásico da etiologia da ferida, cicatrizando completamente após 17 dias.

PALAVRAS-CHAVE: Dermatologia. Neoplasia. Plasma rico em plaquetas.

\section{USE OF PLATELET-RICH PLASMA IN THE TREATMENT OF CUTANEOUS WOUND IN DOGS: A CASE REPORT}

\begin{abstract}
Platelet-rich plasma (PRP) consists of a supra-physiologic platelet concentrate extracted from the patient's autogenous blood, after being properly centrifuged. This report describes the use of PRP in the treatment of cutaneous wound, after excision of mass with 4-month evolution in a 7-year-old beagle bitch. Fine needle aspiration cytology (FNAC) was performed in the mass and suggestive diagnosis of cutaneous adnexal neoplasm was identified. The treatment consisted of mass excision, added by topical and intradermal applications of the studied product in the wound edges. The wound presented decreased inflammatory response, clean healing, uniform edges, and absence of purulent exudate, exaggerated granulation tissue or complications under the neoplastic character of the wound, healing completely after 17 days.
\end{abstract}

KEYWORDS: Dermatology. Neoplasm. Platelet rich plasma.

\section{UTILIZACIÓN DE PLASMA RICO EN PLAQUETAS EN EL TRATAMIENTO DE HERIDA CUTÁNEA EN PERRO: RELATO DE CASO}

RESUMEN: El plasma rico en plaquetas (PRP) consiste en un concentrado supra fisiológico de plaquetas extraído a partir de la sangre autógena del paciente y centrifugado adecuadamente. El presente relato describe la utilización del PRP en el tratamiento de herida cutánea, tras exéresis de masa con evolución de 4 meses en una perra, de la raza Beagle, de 7 años de edad. Citología aspirativa por aguja fina (CAAF), se realizó en la masa y el diagnóstico sugestivo de neoplasia de anexo cutáneo de bajo grado fue identificado. El tratamiento instituido consistió en la escisión de la masa y aplicaciones tópicas e intradérmicas en los bordes de la herida con el producto obtenido. La lesión presentó reducción de la respuesta inflamatoria, cicatrización limpia, bordes uniformes, ausencia de exudado purulento, tejido de granulación exagerado y complicaciones bajo el carácter neoplásico de la etiología de la herida, cicatrizando completamente después de 17 días.

PALABRAS CLAVE: Dermatología. Neoplasia. Plasma rico en plaquetas.

\section{Introdução}

A própria lesão tecidual, independentemente de sua causa, inicia o processo de reparação do tecido (FOSTER et al., 2009). Esse processo é equilibradamente coordenado, a partir da lesão, a nível celular, bioquímico e molecular, e objetiva a cicatrização da ferida, impedindo assim que seja mantida uma porta de entrada de patógenos no organismo (CAMPOS; BORGES-BRANCO; GROTH, 2007).

A cicatrização de tecidos conectivos ocorre em três fases: inflamação, proliferação e remodelamento (FOSTER et al., 2009), e envolve processos complexos e mediadores bioquímicos como citocinas e fatores de crescimento
(WILLIAMS; MOORES, 2009). A fase inflamatória é por vezes subdividida em resposta vascular (hemostasia) e resposta celular (inflamação), e consiste na ativação plaquetária, que leva à formação de coágulos de fibrina e secreção de agentes quimiotáticos. Por sua vez, a fase proliferativa consiste no reparo das estruturas que foram danificadas (epiderme, derme e outras estruturas como vasos sanguíneos, nervos e unidades pilo-sebáceas). Enfim, a fase de remodelamento visa normalizar a espessura da epiderme, conteúdo extracelular e demais estruturas a fim de restabelecê-las o mais próximo possível a um estágio pré-ferida (RITTIÉ, 2016).

No processo de cicatrização podem se desenvolver dois tipos característicos de reparo tecidual: cicatrização por 
primeira intenção e por segunda intenção. Na cicatrização por primeira intenção, verifica-se a formação de coágulo de fibrina que une os bordos da ferida. O coágulo seca em sua superfície, formando uma crosta que bloqueia a lesão exteriormente e auxilia na prevenção de possíveis infecções. A resposta inflamatória induz a vasodilatação, que permite a chegada de grande quantidade de células sanguíneas e demais substâncias ao local da injúria. $\mathrm{O}$ edema surge com o aumento da permeabilidade vascular e novos vasos sanguíneos crescem para revascularizar a área. A fibrina é degradada e o coágulo é substituído por tecido conjuntivo, resultando no tecido de granulação (COSTA; SANTOS, 2016).

A cicatrização por segunda intenção ocorre de forma parcialmente semelhante à cicatrização por primeira intenção. As diferenças se estabelecem em função de que nesse tipo secundário de processo cicatricial, os bordos da ferida encontram-se distantes e, portanto, as células epiteliais levam mais tempo para regenerar e recobrir a lesão. Além disso, o grau de resposta inflamatória é maior e mais detritos celulares são encontrados (COSTA; SANTOS, 2016). Portanto, nessa forma de cicatrização o reparo é lento, passível de infecções e de formação exacerbada de tecido de granulação (SOUZA et al., 2014).

Segundo Khalil et al. (2015), os elementos sistêmicos que influenciam a cicatrização podem ser divididos em: fatores que afetam a cicatrização, comorbidades existentes e medicamentos utilizados. Diante dos mesmos, destaca-se na clínica de pequenos animais, a idade avançada, a não adesão ao tratamento correto, ausência de controle eficiente da dor; e as comorbidades como a hipertensão, hipotensão e diabetes, distúrbios endócrinos/metabólicos, desordens nutricionais, doenças cardiovasculares, infecção, osteoartrite e uso de anticoagulantes.

Em função das dificuldades encontradas em alguns casos clínicos para a cicatrização adequada de feridas, o Plasma Rico em Plaquetas (PRP) caracteriza terapêutica promissora para acelerar e estimular o processo de cura em lesões de pele (MOLINA-MIÑANO et al., 2009). Este tratamento consiste na utilização de um concentrado de plaquetas obtido através da centrifugação do sangue anticoagulado autógeno do paciente, e possui vantagens de estimular a cicatrização sem ser tóxico, sendo o mesmo incapaz de gerar imunorreação (TORRIANI et al., 2005, COSTA; SANTOS, 2016).

No processo de lesão do tecido, a degranulação de plaquetas libera fatores de crescimento na área lesionada e promove a migração e proliferação de células, resultando na formação de novos vasos sanguíneos e tecido de granulação, fatores essenciais para o reparo tecidual (SUZUKI; MORIMOTO; IKADA, 2013). Assim, por meio da utilização do PRP alcança-se concentrações supra fisiológicas dos fatores envolvidos no processo de reparo das lesões, possibilitando sua aplicação diretamente na ferida (RIENZI; MILLER; CUEVAS, 2016).

As plaquetas secretam diferentes tipos de substâncias reparadoras de tecido como proteínas adesivas, fatores de crescimento e citocinas para ativar e recrutar células como neutrófilos, macrófagos e fibroblastos ao local da lesão. Essas células se ligam à matriz extracelular, se diferenciam (macrófagos são ativados) e secretam interleucinas (IL-1 $\alpha$, IL-1 $\beta$ ) e fator de necrose tumoral alfa (TNF- $\alpha$ ). Além disso, há secreção de fator de crescimento de fibroblasto-2 (FGF-2), fator de crescimento semelhante à insulina-1 (IGF-1), e fator de crescimento transformador beta-1 e -2 (TGF-b1, TGF-B2), para ativar a síntese de colágeno, e ainda a secreção de fator de crescimento do endotélio vascular (VEGF), e fator de crescimento derivado de plaquetas (PDGF), para ativar a angiogênese. Todos esses processos determinam a cicatrização adequada do tecido lesionado (DREIFKE; JAYASURIYA; JAYASURIYA, 2015).

Vários estudos acerca da utilização do PRP no tratamento de feridas têm sido realizados. De acordo com as pesquisas de Tambella et al. (2018) e Martins et al. (2012), ambos estudos observaram a diminuição da resposta inflamatória e, durante o período aproximado de uma semana, a ausência de tecido de granulação exuberante além de cicatrização mais limpa e bordo da ferida mais uniforme. Ostvar et al. (2015) constataram redução significativa da lesão quando comparada ao controle. Quanto à regeneração tecidual, Ganceviciene et al. (2012) concluíram que o PRP, quando injetado, promoveu aumento da regeneração tecidual, melhora na vascularização tecidual, angiogênese e indução da síntese de colágeno por meio da estimulação de fibroblastos, e Barrionuevo (2014) verificou que o PRP, independente da fonte, melhora e acelera o processo de cicatrização, comprovando seu potencial terapêutico sobre as lesões cutâneas. Tal produto biológico pode ser utilizado em diferentes áreas, tanto da medicina humana quanto na veterinária: ortopedia (regeneração e revascularização de ossos, cartilagens e tendões), cirurgia e implantodontia buco-maxilo-facial (regeneração e revascularização de ossos e tecidos moles), oftalmologia (fechamento de feridas, reepitelização corneal e revascularização) e dermatologia através de aplicações tópicas ou injeções subcutâneas (restituição da matriz, revascularização e regeneração do folículo piloso) (ETULAIN, 2018).

Considerando as importantes vantagens associadas ao uso de PRP, como o baixo custo de sua obtenção (PINTO; PIZANI, 2015), facilidade de aplicação, elevada aderência no local da lesão (YAMADA, 2012), efeito antimicrobiano contra Staphylococcus aureus e Escherichia coli, e a redução potencial do risco de infecção por esses microrganismos (BIELECKI et al., 2007), desenvolveu-se um protocolo terapêutico utilizando exérese cirúrgica com cicatrização por segunda intenção em massa tumoral de pele associada à administração intradérmica e tópica de PRP, o qual será apresentado na forma de relato de caso. $\mathrm{O}$ estudo teve o objetivo de analisar a viabilidade técnica, como estudo piloto, da utilização do referido protocolo de tratamento para estudos posteriores elaborados com amostragens adequadas, além de apresentar o processo cicatricial de ferida cutânea em cão utilizando o plasma rico em plaquetas como terapêutica principal e os resultados de cicatrização obtidos.

\section{Relato do Caso}

Foi atendida em uma clínica veterinária na cidade de Foz do Iguaçu, Paraná, uma cadela da raça Beagle, com sete anos de idade, $12 \mathrm{~kg}$, apresentando massa ulcerada em face medial de membro posterior direito medindo $2,1 \times 2,7$ $\mathrm{cm}$ (Figura 1), com evolução de quatro meses. A tutora relatou tratamento prévio com pomadas antibióticas e cicatrizantes, sem êxito. Citologia aspirativa por agulha fina (CAAF) foi realizada no tumor e o diagnóstico sugestivo de neoplasia 
de anexo cutâneo de baixo grau foi identificado. A tutora não autorizou o exame histopatológico da amostra para confirmação do diagnóstico.

O tratamento instituído consistiu na excisão do nódulo e cicatrização por segunda intenção da pele com aplicação intradérmica e tópica de PRP no local da lesão cirúrgica, utilizando-se como fundamento técnico os estudos realizados por Lee et al., (2011), e Kim, Park e Park (2009).

$\mathrm{O}$ animal foi submetido à avaliação hematológica prévia à cirurgia (hemograma, ureia, creatinina, alanina transaminase (ALT) e fosfatase alcalina). Todos os índices encontraram-se dentro dos valores de referência para cães, de forma a classificar sua condição pré-anestésica em bom estado clínico, estável, de baixo risco anestésico, e assim, o paciente foi considerado apto para realizar o protocolo anestésico proposto. O protocolo anestésico e analgésico foi realizado mediante sedação com Zoletil ${ }^{\circledR} 50^{1}(0,1 \mathrm{ml} / \mathrm{kg} / \mathrm{IV})$, bloqueio local com Lidocaína $2 \%{ }^{2}(0,2 \mathrm{mg} / \mathrm{kg})$ e analgesia com Dipirona $50 \%{ }^{3}(30 \mathrm{mg} / \mathrm{kg} / \mathrm{SC})$, Tramadol $50 \mathrm{mg}^{4}(4 \mathrm{mg} /$ $\mathrm{kg} / \mathrm{SC})$ e Maxicam $0,2 \% 5(0,2 \mathrm{mg} / \mathrm{kg} / \mathrm{SC})$.

O protocolo anestésico empregado, composto por uma associação de agente anestésico dissociativo e um benzodiazepínico, exigiu a observação quanto uma possível alteração no funcionamento do sistema cardiovascular e respiratório no transcorrer da anestesia (FANTONI; CORTOPASSI, 2018, p. 457). Esta monitorização foi realizada durante toda a vigência anestésica, sendo feita por meio de auscultação cardíaca e pulmonar, com avaliação da frequência respiratória, frequência cardíaca, pressão arterial, tempo de preenchimento capilar e aspecto e coloração das mucosas do paciente. Não houve detecção de alterações cardiorrespiratórias importantes no período cirúrgico, sendo o mesmo transcorrido sem intercorrências. O período de recuperação anestésica teve duração aproximada de 3 horas, e apesar de se esperar uma agitação nesse período, com possível apresentação de êmese, vocalização, movimentos de pedalagem e excitação em geral, em função do protocolo anestésico utilizado (FANTONI; CORTOPASSI, 2018, p. 459), o paciente recuperou-se desse período sem intercorrências, apresentando apenas leve estado cataleptóide.
Figura 1: Massa ulcerada em face medial de membro posterior direito de um cão da raça Beagle com sete anos de idade. A) $2,7 \mathrm{~cm}$, B) $2,1 \mathrm{~cm}$.

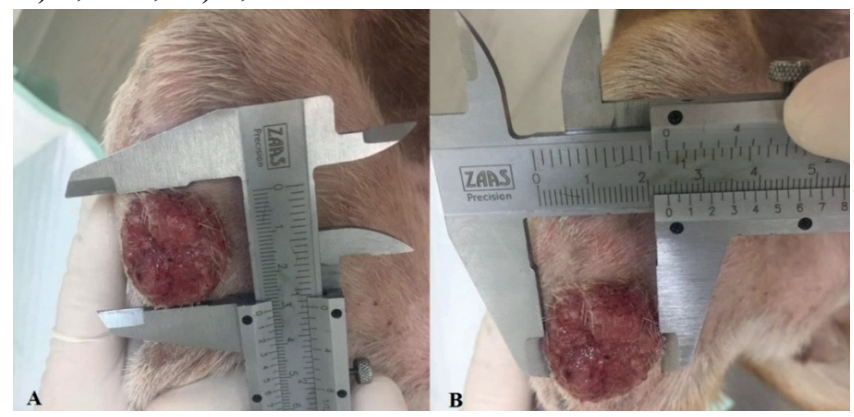

Fonte: Arquivo pessoal

Para extração do PRP, $10 \mathrm{~mL}$ de sangue periférico foram coletados da veia jugular externa e acondicionados em frascos contendo anticoagulante citrato de sódio a 3,2\% (SANTOS, 2016). A primeira etapa da centrifugação se deu a 400g (Centrífuga Clínica Centribio/Daiki 80-2B) durante 10 minutos para formação de dois níveis, um superior com coloração amarelada denominada plasma pobre em plaquetas (PPP) e um inferior avermelhado (Figura 2A).

Toda a fração do plasma e mais $200 \mu \mathrm{L}$ da fração vermelha foram alocados em novos tubos contendo anticoagulante citrato de sódio a $3,2 \%$ e passaram por segunda centrifugação a $400 \mathrm{~g}$ durante 10 minutos (adaptado de Barrionuevo, 2014). O PPP foi desprezado e a porção avermelhada inferior foi aspirada, totalizando $1 \mathrm{~mL}$ de PRP (Figura 2B). As aplicações tópicas e intradérmicas foram realizadas de três a cinco dias, na clínica, durante 17 dias, totalizando cinco aplicações. Durante tratamento não foram administrados antibióticos ou anti-inflamatórios e a limpeza da ferida era realizada diariamente pela tutora com solução fisiológica.

Figura 2: Níveis do plasma evidenciados após primeira centrifugação (A) e segunda centrifugação (B). Em A, após separação do plasma, $200 \mu \mathrm{L}$ da fração vermelha foi submetida à segunda centrifugação. Após segunda centrifugação (B), camada superior (PPP) foi desprezada e PRP foi coletado para aplicação.

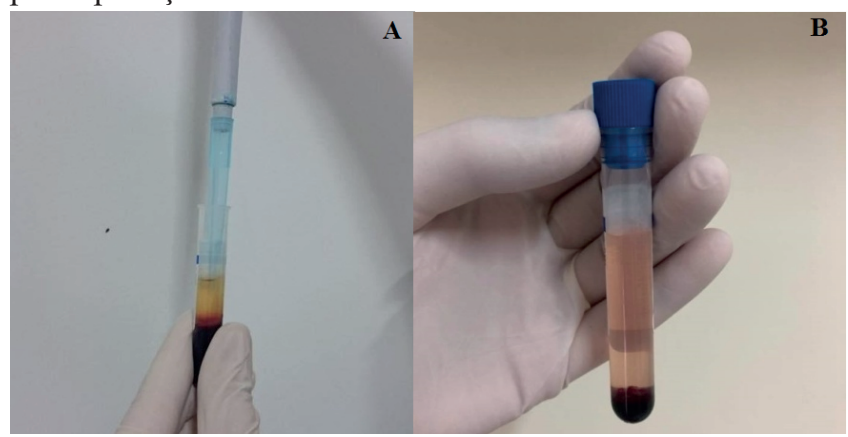

Fonte: Arquivo pessoal

\section{Resultados}

Após 17 dias de tratamento, a ferida apresentou as

'Zoletil 50, Virbac do Brasil Indústria e Comércio LTDA., São Paulo - SP. ${ }^{2}$ Lidovet, Laboratório Bravet LTDA., Rio de Janeiro - RJ.

${ }^{3}$ D500, Zoetis Indústria de Produtos Veterinários LTDA., Campinas - SP. ${ }^{4}$ Cloridrato de tramadol $50 \mathrm{mg} / \mathrm{mL}$, Laboratório TEUTO Brasileiro LTDA., Anápolis - GO

${ }^{5}$ Maxicam 0,2\%, Ouro Fino Saúde Animal LTDA., Cravinhos - SP. medidas: dia $0(2,1 \times 2,7 \mathrm{~cm})$, dia $3(1,5 \times 2,1 \mathrm{~cm})$, $\mathrm{cm}$ ), tendo cicatrizado completamente no dia 17 (Figura 3). A lesão não apresentou sinais de infecção ou exsudato purudia $6(1,4 \times 1,5 \mathrm{~cm})$, dia $11(0,6 \times 0,8 \mathrm{~cm})$, dia $14(0,1 \times 0,5$ 
lento mesmo na ausência de antibióticos e manifestou boa qualidade de tecido cicatricial, além de tempo transcorrido satisfatório (Figura 4).

Figura 3: Tabela de progressão da contração tecidual ao longo tratamento.

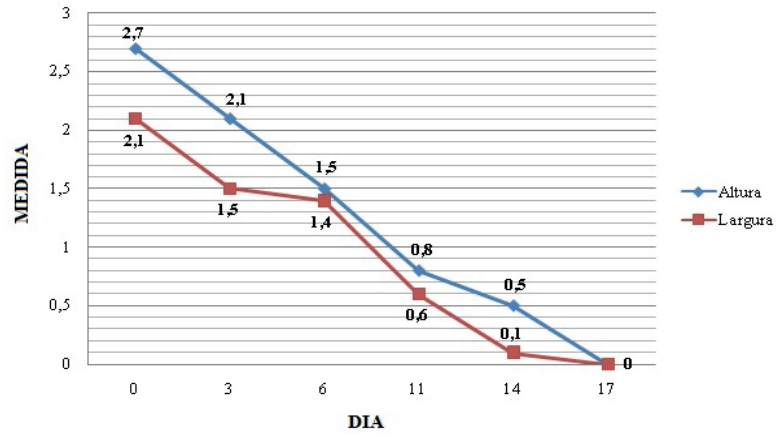

Fonte: Arquivo pessoal

Figura 4: Progressão da contração tecidual ao longo do tratamento, totalizando 17 dias.
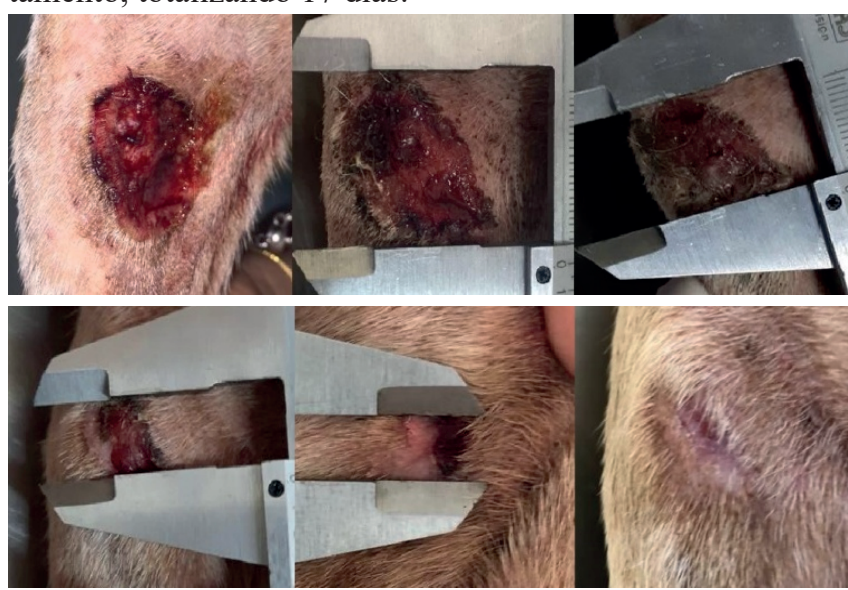

Fonte: Arquivo pessoal

\section{Discussão}

Uma das principais preocupações na utilização do PRP no referido paciente foi o diagnóstico sugestivo de origem neoplásica da ferida (neoplasia de anexo cutâneo de baixo grau), mas apesar da preocupação acerca de um possível efeito carcinogênico local ou sistêmico relacionado à grande quantidade de fatores de crescimento encontrados no PRP (DIGIOVANNI et al., 2000), a ferida não apresentou qualquer proliferação indesejada ou indício de recidiva, cicatrizando de forma esperada 17 dias após exérese tumoral.

Considerando a literatura especializada consultada, e dentre estes, os estudos com utilização criteriosa de PRP em terapia de feridas em cães, elencamos alguns trabalhos publicados e os comparamos aos resultados obtidos pelo protocolo experimental instituído no relato de caso.

Um estudo realizado por Kim, Park e Park (2009) relata o tratamento de lesão extensa em um cão, após exérese de cisto folicular em cauda. Neste estudo a metodologia de obtenção do PRP se desenvolveu mediante coleta de $8 \mathrm{~mL}$ de sangue do paciente, acondicionados em tubo contendo citrato de sódio e centrifugados primeiramente por $10 \mathrm{minu}-$ tos a 629 g. Após a separação das duas camadas, o PRP foi removido com auxílio de uma pipeta, misturado com $200 \mu \mathrm{L}$ da parte inferior e centrifugado novamente a 1233 g por 15 minutos. O produto obtido foi adicionado a uma mistura de igual volume de solução salina estéril com $10 \%$ de cloreto de cálcio. $\mathrm{O}$ sangue da lesão necrótica foi adicionado à mistura, resultando em um gel de PRP $(0,1 \mathrm{~mL})$ utilizado nas aplicações tópicas. Como resultado, a ferida média $2,5 \times 3 \mathrm{~cm}$ e, apesar de apresentar-se eritematosa e exsudativa após o dia 2 , regenerou-se completamente após 4 semanas. Os pesquisadores concluíram que o tratamento tópico pode ser seguro na cicatrização de feridas demoradas.

Apesar do protocolo experimental instituído no relato de caso ter obtido resultados finais similares quando comparado ao referido estudo de Kim, Park e Park (2009), observa-se que no relato destes pesquisadores foi utilizada uma metodologia de obtenção e preparo do PRP distinta do protocolo experimental instituído no relato de caso, o que dificulta inferências mais concretas na comparação do referido estudo ao nosso protocolo.

Outro estudo utilizando-se PRP em cães, igualmente consistente, foi analisado e comparado ao protocolo experimental instituído no relato de caso: o estudo desenvolvido por Zubin et al. (2015). Estes pesquisadores reportaram o manejo de grande lesão cutânea em cão, após atropelamento. Neste estudo, associaram as aplicações de PRP com células tronco derivadas de tecido adiposo (MSCs). O PRP foi preparado após coleta de $25-30 \mathrm{~mL}$ de sangue acondicionados em tubos contendo citrato fosfato dextrose. A primeira centrifugação se deu a $150 \mathrm{~g}$ durante 30 minutos e a fração enriquecida com plaquetas foi centrifugada novamente a 800 g durante 15 minutos. A ferida $(30 \times 35 \mathrm{~cm})$ cicatrizou por completo após 3 meses e nunca apresentou sinais de infecção ou necrose. Apesar da metodologia deste relato não consistir apenas na utilização do PRP, quando comparamos o seu resultado obtido ao do protocolo experimental instituído no relato de caso, também verificamos similaridades de resultado, ou seja, a não ocorrência de infecção e necrose, e obtenção de cicatrização adequada.

Ainda, verificamos que os resultados obtidos em nosso protocolo experimental foram similares aos obtidos por Martins et al. (2012) na utilização de PRP, porém em equinos, onde verificou-se diminuição da resposta inflamatória, cicatrização mais limpa, bordos da ferida mais uniformes e ausência de exsudato purulento.

Finalmente, constatamos que um dos grandes desafios no estudo da utilização do PRP como terapia é a falta de padrão de técnicas de preparação e da ausência de ensaios randomizados de forma a possibilitar inferências mais concretas (ETULAIN, 2018). Outra limitação é a existência de poucos estudos avaliando a habilidade do PRP em cicatrizar feridas cutâneas nas espécies alvo do estudo, cães e gatos, tornando escassas as comparações entre os casos (KIM; PARK; PARK, 2009).

\section{Conclusão}

Após a realização de um tratamento associativo de exérese de massa neoplásica e cicatrização por segunda intenção com a aplicação tópica e intradérmica de PRP, constatou-se os seguintes fatos:

Posteriormente à utilização do protocolo de obtenção do PRP, a ferida apresentou diminuição da resposta 
inflamatória, cicatrização limpa, bordos da ferida uniforme e ausência de exsudato purulento ou tecido de granulação exagerado, e ainda com ausência de complicações sob o caráter neoplásico da etiologia da ferida. Entretanto, apesar da adequação dos resultados para um estudo piloto, sabe-se que há necessidade de ajustes na amostragem de cães com as mesmas características clínicas para uma análise mais aprofundada, no sentido de comparar efeitos de animais tratados e não tratados em uma amostra de indivíduos estatisticamente relevante.

Destaca-se a evidente dificuldade de análise de resultados imposta pela ausência de uma técnica padrão para preparação do plasma rico em plaquetas. Essa situação se torna um desafio a ser enfrentado e ultrapassado para o aprimoramento dos estudos acerca desta terapêutica em cães.

Em função da simplicidade metodológica de obtenção e aplicação do plasma rico em plaquetas instituído neste relato de caso, sugerimos sua utilização em grupos de animais de mesmas características clínicas em uma amostragem maior e estatisticamente determinada para estudos comparativos entre animais tratados e não tratados com PRP, para a validação dos resultados.

\section{Referências}

BARRIONUEVO, D. V. Comparação de feridas induzidas experimentalmente em coelhos tratadas com diferentes fontes de plasma rico em plaquetas. 2014. 27p. Dissertação (Mestrado em Ciência Animal) - Universidade do Oeste Paulista. Presidente Prudente, 2014.

BIELECKI, T. M. et al. Antibacterial effect of autologous platelet gel enriched with growth factors and other active substances: an in vitro study. The Bone \& Joint Journal, v. 89, n. 3, p. 417-420, 2007.

COSTA, P. A.; SANTOS, P. Plasma rico em plaquetas: uma revisão sobre seu uso terapêutico. Revista Brasileira de Análises Clínicas, v. 48, n. 4, p. 311-319, 2016.

CAMPOS, A. C. L.; BORGES-BRANCO, A.; GROTH, A.K. Cicatrização de feridas. ABCD Arquivo Brasileiro de Cirurgia Digestiva, Curitiba, v. 20, n. 1, p. 51-58, 2007.

DIGIOVANNI, J. et al. Constitutive expression of insulinlike growth factor-1 in epidermal basal cells of transgenic mice leads to spontaneous tumor promotion. Cancer Research, v. 60, n. 6, p. 1561-1570, 2000.

DREIFKE, M. B.; JAYASURIYA, A. A.; JAYASURIYA, A. C. Current wound healing procedures and potential care. Materials Science and Engineering: C, v. 48, p. 651-662, 2015 .

ETULAIN, J. Platelets in wound healing and regenerative medicine. Platelets, v. 29, n. 6, p. 556-558, 2018.

FANTONI, D. T.; CORTOPASSI, S. R. G. Anestésicos dissociativos. In: ANDRADE, S. F. Manual de terapêutica veterinária. 3. ed. São Paulo: Roca, 2018, p. 456-460.
FOSTER, T. E. et al. Platelet-rich plasma: from basic science to clinical applications.The American Journal of Sports Medicine, v. 37, n. 11, p. 2259-2272, 2009.

GANCEVICIENE, R. et al. Skin anti-aging strategies. Dermato-endocrinology, v. 4, n. 3, p. 308-319, 2012.

KHALIL, H. et al. Elements affecting wound healing time: an evidence based analysis. Wound Repair and Regeneration, v. 23 , n. 4 , p. $550-556,2015$.

KIM, J. H.; PARK, C.; PARK, H. M. Curative effect of autologous platelet-rich plasma on a large cutaneous lesion in a dog. Veterinary Dermatology, v. 20, n. 2, p. 123-126, 2009.

LEE, J. W. et al. The Efficacy of Autologous Platelet Rich Plasma Combined with Ablative Carbon Dioxide Fractional Resurfacing for Acne Scars: A Simultaneous Split Face Trial. Dermatologic Surgery, v. 37, n. 7, p. 931-938, 2011.

MARTINS, R. K. et al. Tratamento clínico de lesões cutâneas em equinos com plasma rico em plaquetas (PRP) - resultados preliminares. In: SALÃO DE INICIAÇÃO CIENTÍFICA E TECNOLÓGICA, UNIVERSIDADE LUTERANA DO BRASIL, 18., 2012, Canoas. Anais [...], Canoas: ULBRA. Disponível em: http://www.conferencias.ulbra.br/index.php/ sic/xviii/paper/view/132. Acesso em: 31 ago. 2019.

MOLINA-MIÑANO, F. et al. Plasma rich in growth factors and bone formation: a radiological and histomorphometric study in New Zealand rabbits. Brazilian Oral Research, v. 23 , n. 3, p. $275-280,2009$

OSTVAR, O. et al. Retracted article: Effect of platelet-rich plasma on the healing of cutaneous defects exposed to acute to chronic wounds: a clinico-histopathologic study in rabbits. Diagnostic Pathology, v. 10, n. 1, p. 85, 2015.

PINTO, J. M. N.; PIZANI, N. S. Aplicabilidade em dermatologia do plasma rico em plaquetas. Surgical \& Cosmetic Dermatology, v. 7, n. 1, p. 61-64, 2015.

RIENZI, A.; MILlER, A.; CUEVAS, I. Plasma rico en plaquetas: Indicaciones en lesiones deportivas. Tendencias en Medicina, v. 48, p. 145-51, 2016.

RITTIÉ, L. Cellular mechanisms of skin repair in humans and other mammals. Journal of Cell Communication and Signaling, v. 10, n. 2, p. 103-120, 2016.

SANTOS, E. S. S. et al. Assessment of healing of standardized wounds in rabbits treated serially with autologous plateletrich plasma gel. Semina: Ciências Agrárias, v. 37, n. 6, p. 4131-4138, nov./dez. 2016.

SOUZA, M. V. et al. Expressão gênica do colágeno em ferida cutânea de equinos tratada com plasma rico em plaquetas. Pesquisa Veterinária Brasileira, v. 34, n. 3, p. 233-240, 2014. 
SUZUKI, S.; MORIMOTO, N.; IKADA, Y. Gelatin gel as a carrier of platelet-derived growth factors. Journal of Biomaterials Applications, v. 28, n. 4, p. 595-606, 2013.

TAMBELlA, A. M. et al. Platelet-rich plasma to treat experimentally-induced skin wounds in animals: a systematic review and meta-analysis. Plos One, v. 13, n. 1, p. 1-26, 2018.

TORRIANI, M. A. et al. Plasma Rico em Plaquetas: uma Revisão de Literatura. Revista Brasileira de Implantodontia \& Prótese sobre Implantes, v. 12, n. 47/48, 2005.

WILLIAMS, J.; MOORES, A. Manual of canine and feline wound management and reconstruction 2. ed. BSAVA, 2009.

YAMADA, A. L. M. et al. Plasma rico em plaquetas no tratamento de lesões condrais articulares induzidas experimentalmente em equinos: avaliação clínica, macroscópica, histológica e histoquímica. Arquivo Brasileiro de Medicina Veterinária e Zootecnia, v. 64, n.2, p. 318-322, 2012.

ZUBIN, E. et al. Regenerative therapy for the management of a large skin wound in a dog. Clinical Case Reports, v. 3, n. 7, p. 598-603, 2015.

Recebido em: 15.06 .2018 Aceito em: 19.11.2019 